oxygenation would not have achieved effective cardiac decompression in the absence of an interatrial communication, and the need to remove an intracardiac foreign body and perform atrial septectomy required immediate open heart surgery. The EXIT strategy described here could conceivably be used when immediate open heart surgery is required, as an approach to secure a fetus hemodynamically before separation from maternal-placental circulation.

\section{References}

1. Barker GM, Forbess JM, Guleserian KJ, Nugent AW. Optimization of preoperative status in hypoplastic left heart syndrome with intact atrial septum by left atrial decompression and bilateral pulmonary artery bands. Pediatr Cardiol. 2014;35: 479-84.

2. Rychik J, Rome JJ, Collins MH, DeCampli WM, Spray TL. The hypoplastic left heart syndrome with intact atrial septum: atrial morphology, pulmonary vascular histopathology and outcome. J Am Coll Cardiol. 1999:34:554-60.

3. Atz AM, Feinstein JA, Jonas RA, Perry SB, Wessel DL. Preoperative management of pulmonary venous hypertension in hypoplastic left heart syndrome with restrictive atrial septal defect. Am J Cardiol. 1999;83: 1224-8.

4. Chaturvedi RR, Ryan G, Seed M, van Arsdell G, Jaeggi ET. Fetal stenting of the atrial septum: Technique and initial results in cardiac lesions with left atrial hypertension. Int J Cardiol. 2013;168:2029-36.

5. Norris MC, Joseph J, Leighton BL. Anesthesia for perinatal surgery Am J Perinatol. 1989;6:39-40.

\title{
Complete thoracoscopic S9 or S10 segmentectomy through a pulmonary ligament approach
}

\author{
Takuma Kikkawa, MD, Masato Kanzaki, MD, PhD, Tamami Isaka, MD, PhD, and
}

Takamasa Onuki, MD, PhD, Tokyo, Japan

Video clip is available online.

The pulmonary ligament (PL) forms the intersegmental septum and enters the lung parenchyma. ${ }^{1}$ Consequently, the PL can be easily separated from the lung parenchyma at surgery. We report thoracoscopic segmentectomy of the lateral basal segment (S9), the posterior basal segment (S10), or both by a new approach that does not require interlobar separation of the lung.

\section{SURGICAL TECHNIQUE}

Since March 2009, we have performed thoracoscopic segmentectomy of S9, S10, or both through a PL approach in 23 patients in whom a nodular shadow or ground-glass

\footnotetext{
From the Department of Surgery I, Tokyo Women's Medical University, Tokyo, Japan.

Disclosures: Authors have nothing to disclose with regard to commercial support. Received for publication Aug 26, 2014; revisions received Oct 21, 2014; accepted for publication Oct 25, 2014; available ahead of print Nov 22, 2014.

Address for reprints: Masato Kanzaki, MD, PhD, Department of Surgery I, Tokyo Women's Medical University, 8-1 Kawada-cho, Shinjuku-ku, Tokyo 162-8666, Japan (E-mail: kanzaki@twmu.ac.jp).

J Thorac Cardiovasc Surg 2015;149:937-9

$0022-5223 / \$ 36.00$

Copyright (C) 2015 by The American Association for Thoracic Surgery

http://dx.doi.org/10.1016/j.jtcvs.2014.10.111
}

opacity measuring $2 \mathrm{~cm}$ or less was found in S9 or S10 on chest computed tomography. ${ }^{2}$ All patients were evaluated for the absence of extrapulmonary metastatic disease by fludeoxyglucose F 18 (INN fludeoxyglucose [18F]) positron emission tomographic scan before resection. Reconstruction of 3-dimensional models by preoperative computed tomography has been previously described (Figure 1, A). ${ }^{3-5}$ Involved pulmonary vessels and bronchi were identified, and the surgical procedure was determined on the basis of such factors as tumor location and margin status. Surgery was performed with the patient under general anesthesia with single-lung ventilation and positioned in the lateral decubitus position. A small skin incision, 2.5 to $4 \mathrm{~cm}$ in length, was made along the anterior axillary line at the fifth intercostal space. A camera port was placed at the midaxillary line of the seventh or eighth intercostal space, and an assist port was placed at the posterior axillary line of the seventh or eighth intercostal space. First, the PL was incised up to the inferior pulmonary vein, and the basal pulmonary vein was exposed (Figure 1, $B$ and $C$, Figure 2, $A$, and Video 1). Branches of the basal pulmonary vein that had been preoperatively identified on a 3-dimensional image and branches of the segmental pulmonary vein were transected if necessary (Figure 2, $B$ and $E$ ). With right-angle forceps, dissection proceeded along the intersegmental septum to expose the pulmonary arteries running alongside the bronchi, which were then transected (Figure 2, $C$ and $F$ ). When the bronchi 


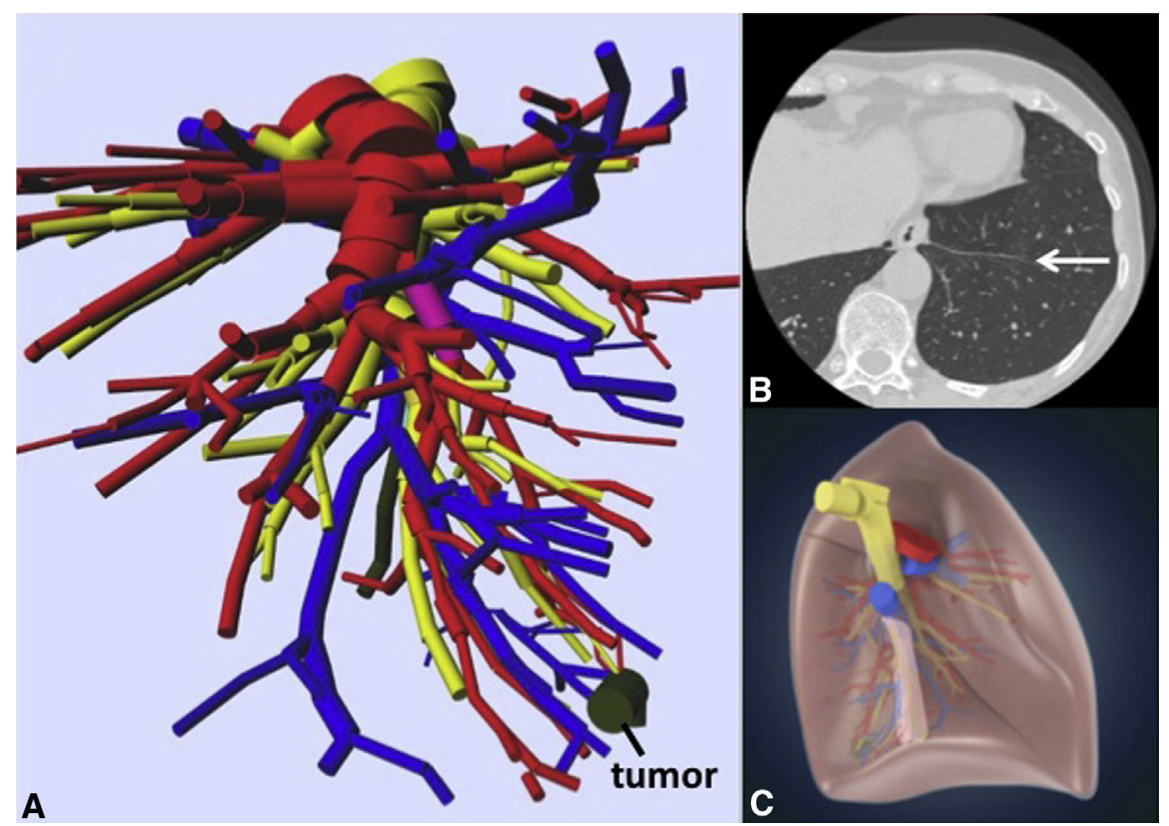

FIGURE 1. A, Three-dimensional model for a patient who underwent posterior basal (S10) segmentectomy of the left lung. Red indicates the pulmonary arteries, blue indicates the pulmonary veins, yellow indicates the trachea and bronchi, and black indicates the tumor. B, The left pulmonary ligament (white arrow) can be seen on chest computed tomography. C, The approach from the pulmonary ligament (light pink) by our technique.

were exposed, the regional lymph nodes were submitted for intraoperative frozen section diagnosis. If lymph node metastasis was confirmed, the procedure was converted to lobectomy. After transection the bronchi and pulmonary arteries (Figure 2, $D$ and $G$ ), the segments were divided. The intersegmental veins were used to identify the intersegmental plane. The segments were divided by the combined use of an electrocautery, an ultrasonically activated device, and a stapler. Interlobular dissection was not performed.

\section{RESULTS}

These 23 patients ranged in age from 15 to 82 years (mean, 62 years). Metastatic lung tumors were diagnosed in 13 patients, early small lung cancers such as adenocarcinoma in situ in 8 , and benign tumors in 2 . The surgical procedures were S9 segmentectomy in 6 patients, S10 segmentectomy in 8, and S9-10 segmentectomy in 9. The operative time ranged from 118 to 261 minutes (mean, $188.3 \pm 43$ minutes). The blood loss ranged from 2 to $332 \mathrm{~mL}$ (mean, $66.3 \pm 79 \mathrm{~mL}$ ). The drainage duration ranged from 2 to 7 days (mean, $3.7 \pm 1.4$ days). No patients required conversion to thoracotomy, and none had air leaks persisting longer than 6 days.

\section{DISCUSSION}

Resection of the basal segments of the lower lobe, particularly S9 or S10 segmentectomy, is considered challenging because the branches of the bronchi and the pulmonary vessels in S9 and S10 are located deep in the lung parenchyma, far from the interlobar fissure. ${ }^{5}$ Conventionally, dissection has been done from the interlobar fissure, making it necessary to cut into the lung parenchyma between the superior segment (S6) and the anterior basal segment (S8), which otherwise would not be required. The PL is contiguous with the intersegmental septum and facilitates entry into the lung parenchyma. The intersegmental septum can be divided into the medial basal segment (S7) and S10 of the right lung, and S8 and S10 of the left lung. ${ }^{1}$ The PL is thus considered useful for intersegmental division of the lung parenchyma during S9 or S10 segmentectomy. The use of 3-dimensional images of the lung facilitates visualization of the positional relations among the target nodule, pulmonary vessels, and bronchi, allowing peripheral vessels and segmental bronchi to be more accurately treated thoracoscopically. Consequently, our technique allowed complete thoracoscopic S9 segmentectomy, S10 segmentectomy, or both to be performed. Our technique may, however, carry a greater risk of incomplete lymph node dissection than do conventional procedures. Early lung cancer showing pure ground-glass opacity on computed tomography, metastatic lung tumors, and benign tumors arising in the center of the lung are considered good indications for our technique.

\section{References}

1. Berkmen YM, Drossman SR, Marboe CC. Intersegmental (intersublobar) septum of the lower lobe in relation to the pulmonary ligament: anatomic, histologic, and CT correlations. Radiology. 1992;185:389-93. 

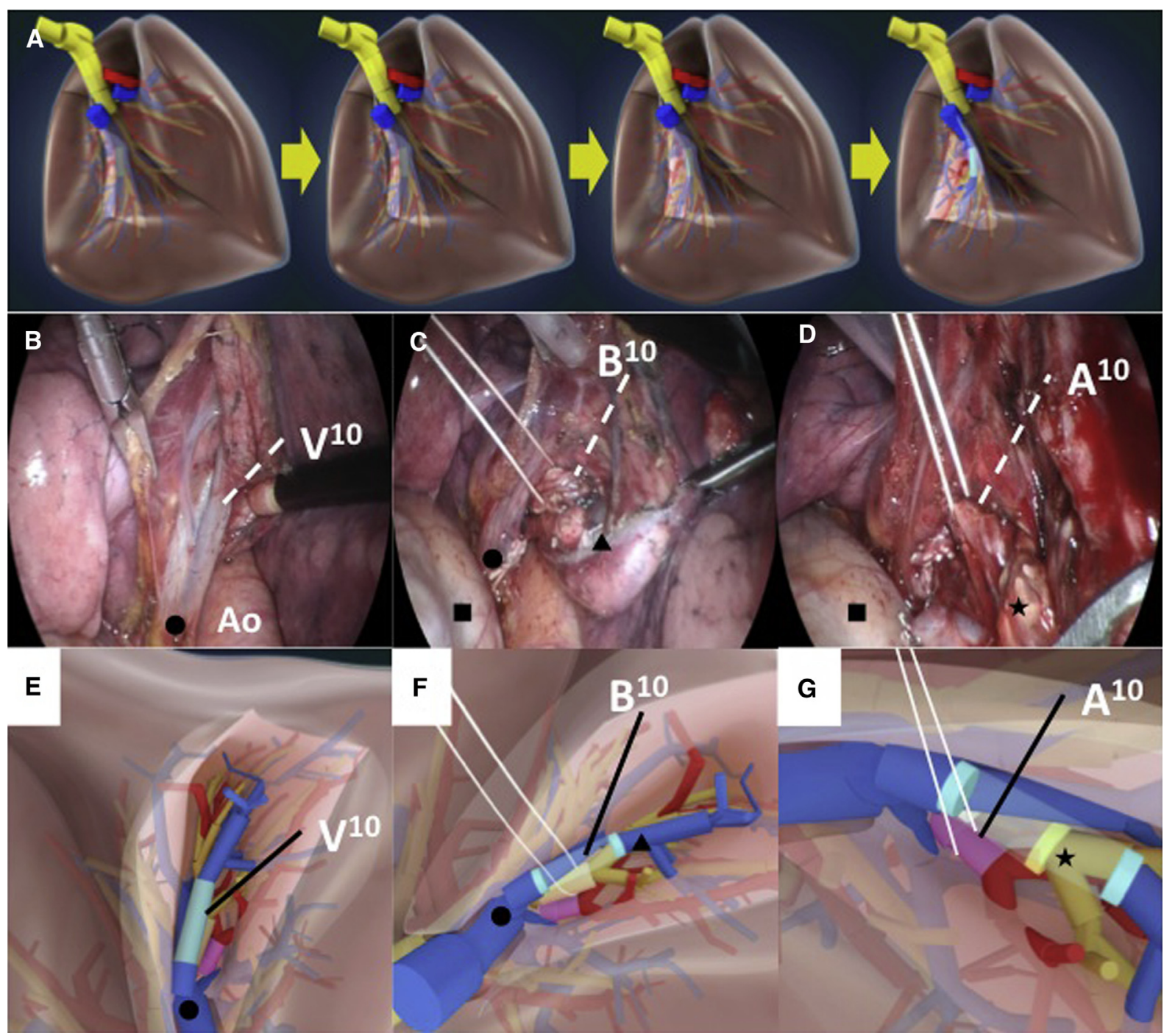

FIGURE 2. A, An image sequence of the visual field when the pulmonary ligament (light pink) was divided by our technique is shown as a 3-dimensional model of the pulmonary vessels and bronchi. B-G, Comparison of the actual surgical field of vision and the 3-dimensional model. B-D, Photographs extracted from digital video data taken during the operation. E-G, Schematic illustrations. Filled circle, Inferior pulmonary vein; filled triangle, stump of the posterior basal vein (V10); filled square, pericardium; filled star, stump of the posterior basal bronchus (B10). Ao, Aorta.

2. Tsutani Y, Miyata Y, Nakayama H, Okumura S, Adachi S, Yoshimura M, et al. Oncologic outcomes of segmentectomy compared with lobectomy for clinical stage IA lung adenocarcinoma: propensity score-matched analysis in a multicenter study. J Thorac Cardiovasc Surg. 2013;146:358-64.

3. Kanzaki M, Kikkawa T, Shimizu T, Maeda H, Wachi N, Isaka T, et al. Presurgical planning using a three-dimensional pulmonary model of the actual anatomy of patient with primary lung cancer. Thorac Cardiovasc Surg. 2013; 61:144-50.
4. Kanzaki M, Maeda H, Wachi N, Kikkawa T, Komine H, Isaka T, et al. Complete video-assisted thoracoscopic multi-subsegmentectomy based on patient's specific virtual 3-D pulmonary models. Asian J Endosc Surg. 2013;6: $110-5$.

5. Oizumi H, Kanauchi N, Kato H, Endoh M, Suzuki J, Fukaya K, et al. Anatomic thoracoscopic pulmonary segmentectomy under 3-dimensional multidetector computed tomography simulation: a report of 52 consecutive cases. J Thorac Cardiovasc Surg. 2011;141:678-82. 